\title{
Letter from the Editors
}

We are happy to present this fall issue of Itinerario, which once again offers a great variety of articles and reviews. Portia Reyes takes us to the Philippines and analyses how Germans reported on the Philippine revolution, while Gregory Barton and Brett Bennett deal with the problem of deforestation in colonial India. Rafael Herzstein gives us a view of the Francophone communities in Beirut at the dawn of the century. It will not go unnoticed that the editorial team was entranced by the charming and exceptional scholar Kees Brouwer. In the interview he reveals much about his exciting and passionate life and we learn how he evolved from a student of Dutch literature into a leading historian of early modern Yemen. We are pleased that, in addition to the interview, he has allowed us to publish his twin articles on the opium and tobacco trade in seventeenth-century Yemen.

The Editors 